\title{
Spiroplasma eriocheiris sp. nov., associated with mortality in the Chinese mitten crab, Eriocheir sinensis
}

\author{
Wen Wang, ${ }^{1}$ Wei Gu, ${ }^{1}$ Gail E. Gasparich, ${ }^{2}$ Keran Bi, ${ }^{1,3}$ Jiangtao Ou, ${ }^{1}$ \\ Oingguo Meng, ${ }^{1}$ Tingming Liang, ${ }^{1}$ Oi Feng, ${ }^{1}$ Jianqiong Zhang ${ }^{4}$ \\ and Ying Zhang ${ }^{4}$
}

Correspondence

Wen Wang

njnuwang@263.net
${ }^{1}$ Jiangsu Key Laboratory for Biodiversity and Biotechnology and Jiangsu Key Laboratory for Aquatic Crustacean Diseases, College of Life Sciences, Nanjing Normal University, Nanjing 210046, PR China

${ }^{2}$ Department of Biological Sciences, Towson University, Towson, MD 21252, USA

3 Jiangsu Key Laboratory for Marine Biotechnology, Huaihai Institute of Technology, Lian, Yungang 222005, PR China

${ }^{4}$ Medical School of Southeast University, Nanjing 210009, PR China

A motile bacterium, designated strain TDA-040725- $5^{\top}$, was isolated from the haemolymph of a Chinese mitten crab, Eriocheir sinensis, with tremor disease. Based on 16S rRNA gene sequence analysis, the strain was phylogenetically distinct from other spiroplasmas but was closely related to Spiroplasma mirum ATCC $29335^{\top}$. Cells of strain TDA-040725-5 ${ }^{\top}$ were variable in length and shape, helical and motile, as determined by phase-contrast light microscopy. Examination by electron microscopy revealed wall-less cells delimited by a single membrane. The strain grew in M1D or R-2 liquid media at $20-40^{\circ} \mathrm{C}$, with optimum growth at $30{ }^{\circ} \mathrm{C}$. Doubling time at the optimal temperature was $24 \mathrm{~h}$. The strain catabolized glucose and hydrolysed arginine but did not hydrolyse urea. The DNA G +C content was $29.7 \pm 1$ mol\%. The genome size was $\sim 1.4-$ $1.6 \mathrm{Mbp}$. Serological analysis, performed using the deformation test, did not reveal any reciprocal titres $\geqslant 320$, indicating that strain TDA-040725-5 $5^{\top}$ had minimal cross-reactivity to strains of recognized species of the genus Spiroplasma. Based on this evidence, strain TDA-040725-5 ${ }^{\top}$ $\left(=\right.$ CCTCC M $207170^{\top}=$ DSM $\left.21848^{\top}\right)$ represents a novel species of the genus Spiroplasma, for which the name Spiroplasma eriocheiris sp. nov. is proposed, belonging to the novel Spiroplasma serological group XLIII.
With the development of aquaculture in China, many diseases affecting farmed aquatic organisms have emerged in recent years, one of which is tremor disease (TD). This disease affects Chinese mitten crabs, Eriocheir sinensis, and has had disastrous effects on aquaculture in China (Wei, 1999). Based on morphological and pathological studies (Wang \& Gu, 2002; Wang et al., 2002; Zhang et al., 2002), the TD agent (TDA) was previously thought to be a rickettsia-like organism. Analysis using universal primers for bacterial 16S rRNA gene sequences showed that the agent was not a rickettsia, but a spiroplasma, showing $98 \%$ $16 \mathrm{~S}$ rRNA gene sequence similarity to Spiroplasma mirum

Abbreviations: CCU, colour-change unit; DF, deformation; MP, maximum-parsimony; ML, maximum-likelihood; TD, tremor disease; TDA, tremor disease agent; TEM, transmission electron microscopy.

The GenBank/EMBL/DDBJ accession number for the 16S rRNA sequence of strain TDA-040725-5 $5^{\top}$ is D0917753.
(Wang et al., 2003, 2004b). This was supported by the fact that the TDA had typical characteristics of spiroplasmas; very small (passing through a $220 \mathrm{~nm}$ membrane filter), mobile, helical, lacking a cell wall and culturable in M1D (Whitcomb et al., 1982) or R2 (Moulder et al., 2002) culture medium. This agent was the first spiroplasma isolated from a freshwater crustacean, challenging our understanding of the range of hosts affected by spiroplasmas (Regassa \& Gasparich, 2006). In studies based on $16 \mathrm{~S}$ rRNA gene sequence analysis, two species of marine shrimp, Alvinocarid shrimp (Rimicaris exoculata) (Zbinden \& Cambon-Bonavita, 2003) and Pacific shrimp (Penaeus vannamei) (Nunan et al., 2004), have also been reported as being hosts for spiroplasmas. The strain of spiroplasma isolated from $P$. vannamei showed $99 \% 16 \mathrm{~S}$ rRNA gene sequence similarity to Spiroplasma insolitum (GenBank accession no. AY771927); it was identified as a novel species, Spiroplasma penaei sp. nov. (Nunan et al., 
2005), and was designated the reference strain for subgroup I-9 of the genus Spiroplasma.

In this paper, the results of a taxonomic study are presented on the causative organism of the TD epizootic in Eriocheir sinensis in China. Using a polyphasic approach, analyses demonstrated that the isolate can be clearly distinguished from its closest phylogenetic neighbour $S$. mirum. Based on the guidelines recommended by Brown et al. (2007) for the taxonomic classification of novel species of spiroplasma, strain TDA-040725- $5^{\mathrm{T}}$ is considered to represent a novel species of the genus Spiroplasma that constitutes a new serogroup of spiroplasma, group XLIII.

Strain TDA- $040725-5^{\mathrm{T}}$ was isolated as previously described by Wang et al. (2005). Cell filtrate was used for in vitro culture in M1D or R2 broth. A pure culture was obtained by serial dilution, determining one colour-change unit (CCU) (Tully, 1983), which represents the number of cells contained in the highest dilution of a cell suspension that will produce a colour change in broth medium. Tubes containing $1 \mathrm{ml}$ medium were inoculated with $0.05 \mathrm{ml}$ liquid culture, incubated at $4,16,20,22,25,28,30,32,35$, $37,40,42$ and $60{ }^{\circ} \mathrm{C}$, and observed daily. Any colour change was noted to determine whether growth was established in each of the tubes. Upon acidification of the culture medium, electron microscopy with negative staining was used, as described previously (Wang et al., 2004a), to examine the media for the presence of cells and to determine their morphology. Spiroplasma mirum ATCC $29335^{\mathrm{T}}$, the suckling mouse cataract agent (Tully et al., 1976, 1977), originally isolated from rabbit ticks (Haemaphysalis leporispalustis) (Tully et al., 1982), was purchased from ATCC and cultured using the same method but incubated at $37{ }^{\circ} \mathrm{C}$.

Cell morphology was determined by phase-contrast microscopy and transmission electron microscopy (TEM) after negative staining. Cell-membrane structure was also determined with TEM using standard ultrathin sectioning

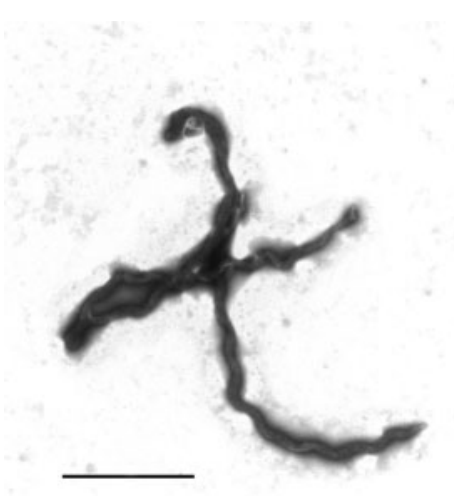

Fig. 1. Electron micrograph of negatively stained spiroplasma from exponential-phase cultures of strain TDA-040725-5 $5^{\top}$. Bar, $2.0 \mu \mathrm{m}$. procedures (Williamson, 1983). Briefly, cells were fixed for $2 \mathrm{~h}$ in $4 \%$ glutaraldehyde, which was added directly to the culture, centrifuged at 8000 r.p.m., post-fixed with $1 \%$ phosphate-buffered osmium tetroxide for $2 \mathrm{~h}$, dehydrated in acetone and embedded in Epon 812 medium. The embedded pellet was cut in to 75-90 nm-thick sections using a Richard Jung Ultracut-E microtome, stained with $2 \%$ aqueous uranyl acetate and lead citrate and viewed with an H-600-2A electron microscope.

To test for sterol requirement, strain TDA-040725- $5^{\mathrm{T}}$ was transferred from R2 medium into a basal medium containing $8 \%$ sucrose and $2.5 \%$ heart infusion broth (HIB) and supplemented with $0,5,10,15$ or $20 \%$ bovine serum. Tests were also carried out in basal medium supplemented with albumin, palmitic acid, Tween 80 and $0,5,10,15$ or $20 \mu \mathrm{g}$ cholesterol $\mathrm{ml}^{-1}$ solubilized in $95 \%$ ethanol. Each test medium was replicated in three tubes. Colour changes in the media were noted to determine whether growth was established. Phase-contrast microscopy was used to examine the media for the presence of cells and to determine cell motility. Negative staining followed by electron microscopy was used to examine cell morphology. Growth was assessed by monitoring the number of CCU ml ${ }^{-1}$ every 3 days (Tully et al., 1983).

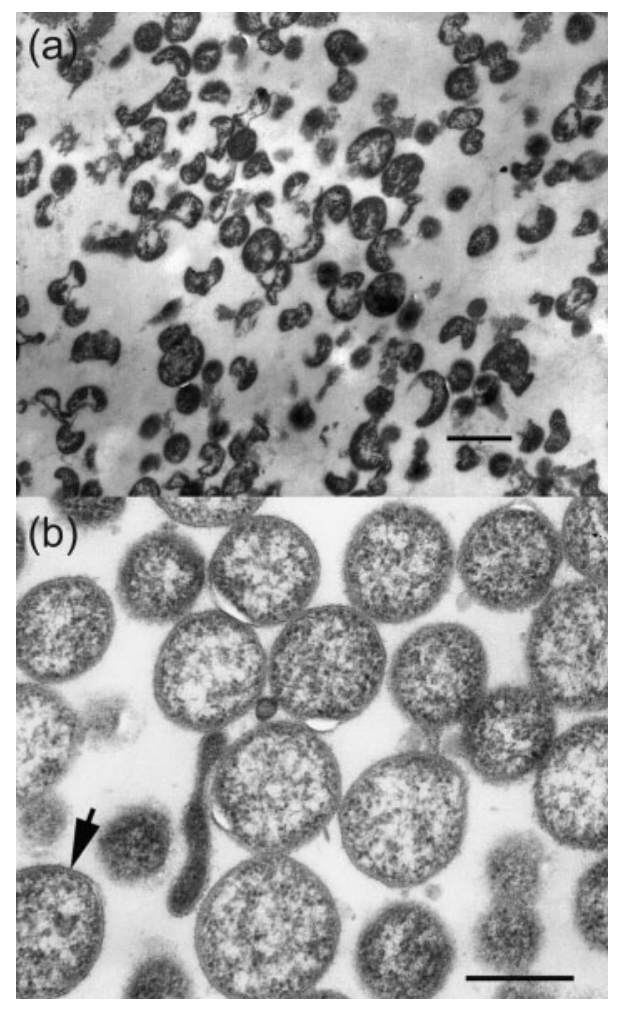

Fig. 2. Electron micrographs of a sectioned and stained pellet from strain TDA-040725-5 $5^{\top}$. The sections were stained with lead citrate and uranyl acetate and observed at both low magnification (bar, $0.5 \mu \mathrm{m}$ ) (a) and high magnification (bar, $0.1 \mu \mathrm{m}$ ) (b). Arrow indicates the single cytoplasmic membrane. 
Table 1. Growth response of strain TDA-040725-5 $5^{\top}$ to cholesterol (sterol)

HIB, Heart infusion broth; NG, no growth.

\begin{tabular}{|c|c|c|c|c|}
\hline \multirow[t]{2}{*}{ Basal medium } & \multirow[t]{2}{*}{ Bovine serum or cholesterol supplement } & \multicolumn{3}{|c|}{$\begin{array}{c}\text { Spiroplasma titres } \\
\left(\mathrm{CCU} \mathrm{ml} \mathrm{ml}^{-1}\right) \text { after incubation at } 30{ }^{\circ} \mathrm{C}\end{array}$} \\
\hline & & Day 3 & Day 6 & Day 9 \\
\hline \multirow[t]{3}{*}{$8 \%$ Sucrose, $2.5 \%$ HIB + bovine serum } & $20 \%$ & $10^{9}$ & $10^{9}$ & $10^{9}$ \\
\hline & $15 \%$ & $10^{9}$ & $10^{9}$ & $10^{9}$ \\
\hline & $10 \%$ & $10^{7}$ & $10^{8}$ & $10^{8}$ \\
\hline \multirow{5}{*}{$\begin{array}{l}8 \% \text { Sucrose, } 2.5 \% \text { HIB, } 1 \% \text { albumin, } 20 \mu \mathrm{g} \\
\text { palmitic acid } \mathrm{ml}^{-1}, 0.01 \% \text { Tween } 80+ \\
\text { cholesterol }\end{array}$} & $20 \mu \mathrm{g} \mathrm{ml}^{-1}$ & $10^{9}$ & $10^{9}$ & $10^{9}$ \\
\hline & $15 \mu \mathrm{g} \mathrm{ml}^{-1}$ & $10^{9}$ & $10^{9}$ & $10^{9}$ \\
\hline & $10 \mu \mathrm{g} \mathrm{ml}^{-1}$ & $10^{8}$ & $10^{9}$ & $10^{9}$ \\
\hline & $5 \mu \mathrm{g} \mathrm{ml}^{-1}$ & $10^{7}$ & $10^{8}$ & $10^{8}$ \\
\hline & $0 \mu \mathrm{g} \mathrm{ml}^{-1}$ & NG & NG & NG \\
\hline
\end{tabular}

Procedures for determining carbohydrate fermentation and arginine and urea hydrolysis were performed as described by Aluotto et al. (1970). The ability of cells to pass through a $220 \mathrm{~nm}$ filter membrane and the requirement of serum for growth were determined using R2 broth, following procedures previously described by Tully (1983). All tests were repeated in triplicate.

Utilization of D-glucose, D-fructose, xylose, rhamnose, seminose and D-sorbitol was determined by inoculating strain TDA-040725-5 ${ }^{\mathrm{T}}$ into basal supply medium (BSM: $2.5 \% \mathrm{HIB} ; 0.2 \% \mathrm{NaCl} ; 15 \%$ bovine serum fraction) supplemented with $5 \%$ of one of the carbohydrates listed above. Cells were inoculated into R2 broth and BSM as positive and negative controls (Aluotto et al., 1970; Ye \& Chen, 1991). Colour changes in the media were noted to determine whether growth was established. Phase-contrast microscopy and electron microscopy with negative staining were used to examine cell motility and morphology.

For serological tests, anitserum to strain TDA-040725-5 ${ }^{\mathrm{T}}$ was produced in a rabbit as described by Wang et al. (2009). The Spiroplasma deformation (DF) test was used as described by Williamson et al. (1978) to compare strain TDA-040725- $5^{\mathrm{T}}$, serologically, with strains of species of the genus Spiroplasma with which it shared $>0.94 \% 16 \mathrm{~S}$ rRNA gene sequence similarity. These included strains of the following taxa: Spiroplasma citri (I-1), S. melliferum (I-2), S. kunkelii (I-3), Spiroplasma sp. 277F (I-4), Spiroplasma sp. LB-12 (I-5), S. insolitum (I-6), Spiroplasma sp. N525 (I7), S. phoeniceum (I-8), S. penaei (I-9), S. poulsonii (II), S. mirum (V), S. syrphidicola (VIII-1), S. chrysopicola (VIII-2) and Spiroplasma sp. TAAS-1 (VIII-3). Antisera for these strains were produced following the protocols of Williamson et al. (1978) and Wang et al. (2009) at the time of taxonomic classification. A complete set of antisera for all strains is maintained at Towson University (Gasparich laboratory), USA. Reciprocal reactions were performed when any positive reactions were observed in the one-way reactions.
Genomic analysis was performed as described previously (Bi et al., 2008) using DNA extracted from cells of strain TDA$040725-5^{\mathrm{T}}$ grown in R2 medium. This process was repeated three times using Escherichia coli DNA (diluted in the same buffer) as a control. 16S rRNA gene sequences used in this study and their GenBank accession numbers are provided in Fig. 3. Sequences were aligned by using CLUSTAL_X version 1.8 (Thompson et al., 1997). Phylogenetic analyses were performed using maximum-parsimony (MP) and maximum-likelihood (ML) methods with PAUP version $4.0 \mathrm{~b} 10$ (Swofford, 2002). Bootstrap values, based on 1000 replications, were obtained by the random stepwise-addition of taxa, repeated 10 times. The model of nucleotide sequence evolution and ML parameters were estimated using Modeltest 3.06 software (Posada \& Crandall, 1998).

Cells of strain TDA-040725- $5^{\mathrm{T}}$ grown to mid-exponential phase in M1D or R2 medium were long, helical, motile filaments, 3-20 $\mu \mathrm{m}$ long and $0.1-0.2 \mu \mathrm{m}$ in diameter (Fig. $1)$. One end of the cells was usually more pointed than the other. Electron microscopy of ultrathin sections of pellets obtained from cultures of strain TDA-040725-5 ${ }^{\mathrm{T}}$ (Fig. 2a) showed cells with a single cytoplasmic membrane and no evidence of a cell wall (Fig. 2b).

Strain TDA-040725-5 $5^{\mathrm{T}}$ grew normally in M1D or R2 with 15$20 \%$ bovine serum fraction but did not grow in media with $<5 \%$ bovine serum fraction. In media with $10 \%$ bovine serum fraction, the strain did multiply but its morphology was abnormal, showing swollen cells (Table 1). Cells could recover from this abnormality back to a helical filamentous form when the bacterium was recultivated in M1D or R2 medium with $15-20 \%$ serum. The strain was maintained through serial passage in media with a serum supplement and could not be maintained through two consecutive 10-fold serial passages in medium without serum supplement, indicating that serum is a requirement of growth.

Strain TDA-040725-5 $5^{\mathrm{T}}$ fermented glucose and hydrolysed arginine but did not hydrolyse urea. Filtration studies indicated that a $48 \mathrm{~h}$ R2 broth culture of TDA-040725-5 
Table 2. Serological relationship between strain TDA$040725-5^{\top}$ and $S$. mirum by the deformation test

Strains: 1, TDA-040725-5 $5^{\mathrm{T}}$; 2, S. mirum ATCC $29335^{\mathrm{T}}$. Titres are given as reciprocals of the final dilution of antiserum in which onehalf of the spiroplasmas were deformed.

\begin{tabular}{|lrr|}
\hline & \multicolumn{2}{c|}{ Antigen } \\
\cline { 2 - 3 } Antiserum & $\mathbf{1}$ & $\mathbf{2}$ \\
\hline 1 & 2048 & 160 \\
2 & 80 & 1024 \\
\hline
\end{tabular}

contained $\sim 10^{9} \mathrm{CCU} \mathrm{ml}^{-1}$. Cultures passed through 0.45 and $0.22 \mu \mathrm{m}$ membrane filters contained $\sim 10^{9}$ and $\sim 10^{8}$ CCU ml $\mathrm{m}^{-1}$, respectively, after filtration. Strain TDA$040725-5^{\mathrm{T}}$ grew at $20-40{ }^{\circ} \mathrm{C}$, with optimal growth at $30{ }^{\circ} \mathrm{C}$.

The Spiroplasma DF test using antisera (Wang et al., 2009) from strain TDA-040725-5 $5^{\mathrm{T}}$ showed no reaction with nine group I, one group II or three group VIII subgroup reference strains. Reciprocal cross-reactivity was observed using S. mirum as an antigen and antiserum as indicated in Table 2. Strain resolution to group placement requires a reciprocal DF titre $\geqslant 320$. This was not observed in any of the DF tests performed in this study according to the minimal standards for taxonomic characterization of novel species of the class Mollicutes (Brown et al., 2007).

The genome size of strain TDA-040725-5 $5^{\mathrm{T}}$ was 1.41.6 Mbp as determined by PFGE (Bi et al., 2008). The genome size of $S$. mirum $\mathrm{SMCA}^{\mathrm{T}}$ was previously determined as 1.2-1.3 Mbp (Tully et al., 1976; Carle et al., 1995). The DNA G $+\mathrm{C}$ content of strain TDA-040725-5 ${ }^{\mathrm{T}}$ was determined, giving results of $29.56,29.80$ and $29.85 \mathrm{~mol} \%$ (mean $29.7 \pm 1 \mathrm{~mol} \%$ ).
Phylogenetic trees (Fig. 3) constructed by using MP and ML methods grouped strain TDA-040725- $5^{\mathrm{T}}$ consistently with the group $\mathrm{V}$ spiroplasma cluster and it was most closely associated with $S$. mirum, the only member of the group V spiroplasmas (Gasparich et al., 2004).

Phylogenetic analysis of strain TDA-040725-5 $5^{\mathrm{T}}$ has been described in detail by $\mathrm{Bi}$ et al. (2008) with analysis of partial nucleotide sequences of $16 \mathrm{~S}$ rRNA, gyrB and $r p o B$ genes, as well as complete $23 \mathrm{~S}$ rRNA gene sequences and 16S-23S rRNA intergenetic spacer regions. For comparison, sequences from closely related species or strains of the genus Spiroplasma were obtained from the GenBank database (Regassa et al., 2004). These sequences clearly showed that strain TDA-040725-5 ${ }^{\mathrm{T}}$ belonged to the Mirum clade and showed a close relationship with S. mirum.

Strain TDA-040725-5 $5^{\mathrm{T}}$ was isolated from the haemolymph of a Chinese mitten crab, Eriocheir sinensis, with tremor disease. The pathogen exhibited a predilection for muscle, nerve and connective tissues and was transported to various tissues and organs by haemocytes. The infected cells had inclusions that stained purple with Giemsa stain. The pathology seen in experimentally infected crabs was similar to that seen in naturally occurring TD (Wang \& Gu, 2002).

The properties described here for strain TDA-040725-5 $5^{\mathrm{T}}$ fulfil the proposed criteria and revised minimal standards for description of new species of the class Mollicutes as described in Brown et al. (2007). Serological comparisons of strain TDA-040725-5 $5^{\mathrm{T}}$ with type strains representing all groups and subgroups of the genus Spiroplasma with which it showed $>94 \% 16 \mathrm{~S}$ rRNA gene sequence similarity demonstrated the uniqueness of the strain. It is therefore proposed that this organism be designated as the reference strain of a novel serological group of the genus Spiroplasma,

(a)

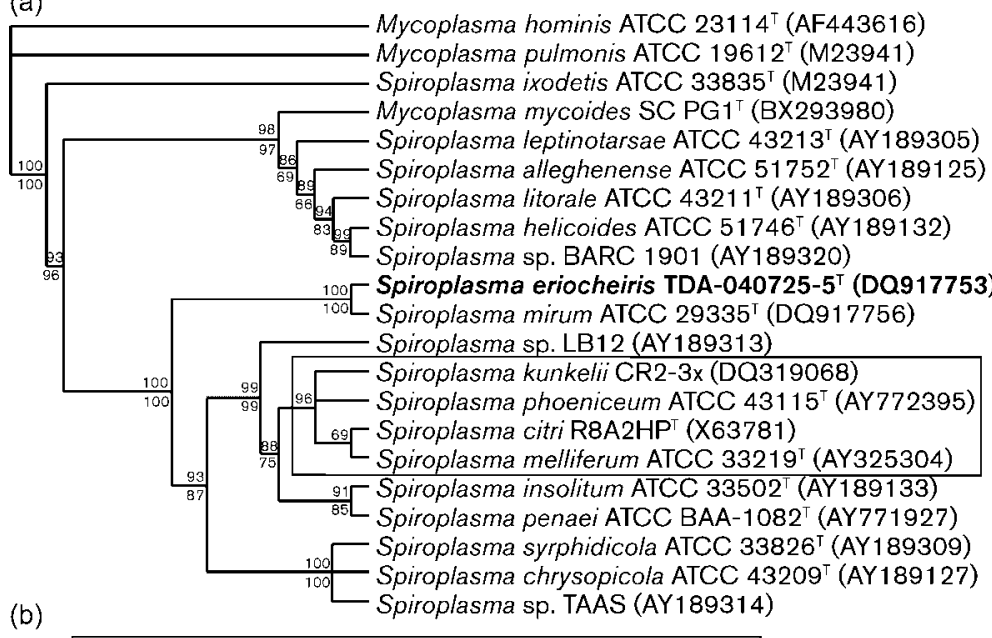

(b)

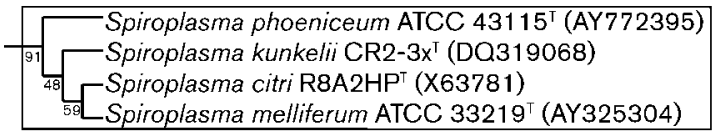

Fig. 3. Phylogenetic tree showing the position of strain TDA-040725-5 $5^{\top}$ among representatives of the genera Spiroplasma and Mycoplasma. (a) MP and $\mathrm{ML}$ trees derived from the 16S rRNA gene partial sequences. Mycoplasma hominis and Mycoplasma pulmonis were used as outgroups. The dataset was resampled 1000 times and bootstrap percentage values are indicated for each branch. Numbers above and below branches represent the bootstrap values of the MP and $M L$ analyses, respectively. (b) A branch of the $M L$ tree that differed to the corresponding branch in the MP tree. 
designated group XLIII. The phenotypic and morphological characteristics of this organism, such as its helical shape, motility and inability to hydrolyse urea, together with its phylogenetic position based on 16S rRNA gene sequence analyses indicate that strain TDA-040725-5 ${ }^{\mathrm{T}}$ represents a novel species of the genus Spiroplasma, for which the name Spiroplasma eriocheiris sp. nov. is proposed.

\section{Description of Spiroplasma eriocheiris sp. nov.}

Spiroplasma eriocheiris (e.ri.o.cheir'is. N.L. n. Eriocheir a genus of crab; N.L. gen. n. eriocheiris of Eriocheir sinensis, the species of crab from which the organism was isolated).

Cells are helical, motile filaments with a mean diameter of $190 \mathrm{~nm}$ and lack true cell walls. Acid is produced from glucose and arginine is hydrolysed. Grows at $20-40{ }^{\circ} \mathrm{C}$ (optimum $30{ }^{\circ} \mathrm{C}$ ) in M1D or R2 broth. Genome size is 1.41.6 Mbp. The DNA G $+\mathrm{C}$ content of the type strain is $29.7 \pm 1 \mathrm{~mol} \%$.

The type strain, TDA-040725- $5^{\mathrm{T}}\left(=\right.$ CCTCC M $207170^{\mathrm{T}}$ $=$ DSM $21848^{\mathrm{T}}$ ), was isolated from haemolymph of the Chinese mitten crab, Eriocheir sinensis, to which the organism is pathogenic, and is serologically distinct from closely related species of the genus Spiroplasma.

\section{Acknowledgements}

We are thankful to Professor O. Roger Anderson and Ms Linda Nunan for correcting the manuscript and $\mathrm{Mr}$ Kaihe Du for TEM technical assistance. This work was supported by grants from the National Natural Sciences Foundations of China (NSFC; nos 30771649 and 30870090) and the Project for Aquaculture in Jiangsu Province (no. J2009-43).

\section{References}

Aluotto, B. B., Wittler, R. G., Williams, C. O. \& Faber, J. E. (1970). Standardized bacteriologic techniques for the characterization of Mycoplasma species. Int J Syst Bacteriol 20, 35-58.

Bi, K., Huang, H., Gu, W., Wang, J. \& Wang, W. (2008). Phylogenetic analysis of spiroplasmas from three freshwater crustaceans (Eriocheir sinensis, Procambarus clarkia and Penaeus vannamei) in China. J Invertebr Pathol 99, 57-65.

Brown, D. R., Whitcomb, R. F. \& Bradbury, J. M. (2007). Revised minimal standards for description of new species of the class Mollicutes (division Tenericutes). Int J Syst Evol Microbiol 57, 27032719.

Carle, P., Laigret, F., Tully, J. G. \& Bové, J. M. (1995). Heterogeneity of genome sizes within the genus Spiroplasma. Int J Syst Bacteriol 45, 178-181.

Gasparich, G. E., Whitcomb, R. F., Dodge, D., French, F. E., Glass, J. \& Williamson, D. L. (2004). The genus Spiroplasma and its non-helical descendants: phylogenetic classification, correlation with phenotype and roots of the Mycoplasma mycoides clade. Int J Syst Evol Microbiol 54, 893-918.

Moulder, R. W., French, F. E. \& Chang, C. J. (2002). Simplified media for spiroplasmas associated with tabanid flies. Can J Microbiol 48, $1-6$.
Nunan, L. M., Pantoja, C. R., Salazar, M., Aranguren, F. \& Lightner, D. V. (2004). Characterization and molecular methods for detection of a novel spiroplasma pathogenic to Penaeus vannamei. Dis Aquat Organ 62, 255-264.

Nunan, L. M., Lightner, D. V., Oduori, M. A. \& Gasparich, G. E. (2005). Spiroplasma penaei sp. nov., associated with mortalities in Penaeus vannamei, Pacific white shrimp. Int J Syst Evol Microbiol 55, 23172322.

Posada, D. \& Crandall, K. A. (1998). MODELTEST: testing the model of DNA substitution. Bioinformatics 14, 817-818.

Regassa, L. B. \& Gasparich, G. E. (2006). Spiroplasmas: evolutionary relationships and biodiversity. Front Biosci 11, 2983-3002.

Regassa, L. B., Stewart, K. M., Murphy, A. C., French, F. E., Lin, T. \& Whitcomb, R. F. (2004). Differentiation of group VIII Spiroplasma strains with sequences of the 16S-23S rDNA intergenic spacer region. Can J Microbiol 50, 1061-1067.

Swofford, D. L. (2002). PAUP*: Phylogenetic analysis using parsimony (and other methods), version 4.0b10. Sunderland, MA: Sinauer Associates.

Thompson, J. D., Gibson, T. J., Plewniak, F., Jeanmougin, F. \& Higgins, D. G. (1997). The CLUSTAL_X windows interface: flexible strategies for multiple sequence alignment aided by quality analysis tools. Nucleic Acids Res 25, 4876-4882.

Tully, J. G. (1983). Cloning and filtration techniques for mycoplasmas. Methods Mycoplasmol 1, 173-177.

Tully, J. G., Whitcomb, R. F., Williamson, D. L. \& Clark, H. F. (1976). Suckling mouse cataract agent is a helical wall-free prokaryote (spiroplasma) pathogenic for vertebrates. Nature 259, 117-120.

Tully, J. G., Whitcomb, R. F., Clark, H. F. \& Williamson, D. L. (1977). Pathogenic mycoplasmas: cultivation and vertebrate pathogenicity of a new spiroplasma. Science 195, 892-894.

Tully, J. G., Whitcomb, R. F., Rose, D. L. \& Bove, J. M. (1982). Spiroplasma mirum, a new species from the rabbit tick (Haemaphysalis leporispalustris). Int J Syst Bacteriol 32, 92-100.

Tully, J. G., Whitcomb, R. F., Rose, D. L., Williamson, D. L. \& Bové, J. M. (1983). Characterization and taxonomic status of tick spiroplasmas: a review. Yale J Biol Med 56, 599-603.

Wang, W. \& Gu, Z. (2002). Rickettsia-like organism associated with tremor disease and mortality of the Chinese mitten crab Eriocheir sinensis. Dis Aquat Organ 48, 149-153.

Wang, W., Zhu, N., Gu, Z., Du, K. \& Xu, Z. (2002). Study on the transmission of tremor disease (TD) in the Chinese mitten crab, Eriocheir sinensis (Crustacea: Decapoda). J Invertebr Pathol 81, 202204.

Wang, W., Rong, L., Gu, W., Du, K. \& Chen, J. (2003). Study on experimental infections of Spiroplasma from the Chinese mitten crab in crayfish, mice and embryonated chickens. Res Microbiol 154, 677680.

Wang, W., Chen, J., Du, K. \& Xu, Z. (2004a). Morphology of spiroplasmas in the Chinese mitten crab Eriocheir sinensis associated with tremor disease. Res Microbiol 155, 630-635.

Wang, W., Wen, B., Gasparich, G. E., Zhu, N., Rong, L., Chen, J. \& Xu, Z. (2004b). A spiroplasma associated with tremor disease in the Chinese mitten crab (Eriocheir sinensis). Microbiology 150, 3035-3040.

Wang, W., Gu, W., Ding, Z., Ren, Y., Chen, J. \& Hou, Y. (2005). A novel Spiroplasma pathogen causing systemic infection in the crayfish Procambarus clarkii (Crustacea: Decapod), in China. FEMS Microbiol Lett 249, 131-137.

Wang, J., Huang, H., Feng, O., Liang, T., Bi, K., Gu, W., Wang, W. \& Shields, J. D. (2009). Enzyme-linked immunosorbent assay for the 
detection of pathogenic spiroplasma in commercially exploited crustaceans from China. Aquaculture 292, 166-171.

Wei, Z. (1999). [An investigation on the epidemiology of tremor disease of the Chinese mitten crab, Eriocheir sinensis]. Freshw Fish 7, 16-71 (in Chinese).

Whitcomb, R. F., Tully, J. G., Rose, D. L., Stephens, E. B., Smith, A., McCoy, R. E. \& Barile, M. F. (1982). Wall-less prokaryotes from fall flowers in central United States and Maryland. Curr Microbiol 7, 285290.

Williamson, D. L. (1983). Specialized electron microscopic techniques for spiroplasmas in plant and insect tissues. Methods Mycoplasmol 1, $71-76$.
Williamson, D. L., Whitcomb, R. F. \& Tully, J. G. (1978). The spiroplasma deformation test, a new serological method. Curr Microbiol 1, 203-207.

Ye, X. \& Chen, Y. (1991). [Isolation, cultivation, and nutrition characters of spiroplasmas from flowers]. J Nanjing Agricultural University 14, 58-62 (in Chinese).

Zbinden, M. \& Cambon-Bonavita, M. A. (2003). Occurrence of Deferribacterales and Entomoplasmatales in the deep-sea Alvinocarid shrimp Rimicaris exoculata gut. FEMS Microbiol Ecol 46, 23-30.

Zhang, F., Wang, J., Zhu, Q. \& Zhou, G. (2002). [Electron microscopy of pathologen of appendage shaking disease of Eriocheir sinensis]. J Dalian Fisheries University 17, 336-340 (in Chinese). 